\title{
Diagnosis and Management of Acute Coronary Syndrome: An Evidence-Based Update
}

\author{
Jennifer N. Smith, PharmD, BCPS, Jenna M. Negrelli, PharmD, BCPS, \\ Megha B. Manek, MD, Emily M. Hawes, PharmD, BCPS, and Anthony J. Viera, MD
}

Acute coronary syndrome (ACS) describes the range of myocardial ischemic states that includes unstable angina, non-ST elevated myocardial infarction (MI), or ST-elevated MI. ACS is associated with substantial morbidity and mortality and places a large financial burden on the health care system. The diagnosis of ACS begins with a thorough clinical assessment of a patient's presenting symptoms, electrocardiogram, and cardiac troponin levels as well as a review of past medical history. Early risk stratification can assist clinicians in determining whether an early invasive management strategy or an initial conservative strategy should be pursued and can help determine appropriate pharmacologic therapies. Key components in the management of ACS include coronary revascularization when indicated; prompt initiation of dual antiplatelet therapy and anticoagulation; and consideration of adjuvant agents including $\beta$ blockers, inhibitors of the renin angiotensin system, and $\mathrm{HmG}$-coenzyme A reductase inhibitors. It is essential for clinicians to take an individualized approach to treatment and consider long-term safety and efficacy when managing patients with a history of ACS after hospital discharge. ( $\mathrm{J}$ Am Board Fam Med 2015;28:283-293.)

Keywords: Acute Coronary Syndrome, Cardiology, Myocardial Infarction

Acute coronary syndrome (ACS) describes the range of myocardial ischemic states that includes unstable angina (UA), non-ST elevated myocardial infarction (NSTEMI), or ST-elevated myocardial infarction (STEMI). The diagnosis and classification of ACS is based on a thorough review of clinical features, including electrocardiogram (ECG) findings and biochemical markers of myocardial necrosis. ${ }^{1} \mathrm{UA}$ is defined by the pres-

This article was externally peer reviewed.

Submitted 26 June 2014; revised 12 October 2014; accepted 20 October 2014.

From the Department of Pharmacy, University of North Carolina Medical Center, Chapel Hill, NC (JNS, JMN, EMH); Department of Family Medicine, Guthrie/Robert Packer Hospital, Sayre, PA (MBM); Department of Family Medicine, University of North Carolina School of Medicine, Chapel Hill, NC (EMH, AJV)

Current affiliation: Philadelphia College of Pharmacy, University of the Sciences in Philadelphia, PA (JNS); Intermountain Medical Center in Murray, UT (JMN).

Funding: none.

Conflict of interest: none declared.

Corresponding author: Jennifer N. Smith, PharmD, BCPS, Philadelphia College of Pharmacy at University of the Sciences, 600 S 43rd Street, Philadelphia, PA 19104 (E-mail: j.smith@usciences.edu). ence of ischemic symptoms without elevations in biomarkers and transient, if any, ECG changes. ${ }^{2}$ The term myocardial infarction (MI) is used when there is evidence of myocardial necrosis in the setting of acute myocardial ischemia. STEMI is differentiated from NSTEMI by the presence of persistent ECG findings of ST segment elevation. ${ }^{3}$ In recent years, progress has been made in the management of ACS, particularly related to optimizing pharmacotherapy. ${ }^{2,3}$ Family physicians care for patients presenting with ACS in office as well as emergency settings and play an important role in both acute and long-term management of such patients. In this article, we review the topic of ACS with particular emphasis on initial management and use of the newer medications. Specific coronary interventions performed by the cardiologist (eg, stents or balloon angioplasty) are beyond the scope of this review.

\section{Scope of the Problem}

Coronary heart disease (CHD) is responsible for more than half of all cardiovascular events in individuals less than 75 years of age. The prevalence of 
CHD is estimated to be $6.4 \%$ in United States (US) adults greater than or equal to 20 years of age, which represents approximately 15.4 million Americans. During the past several years, the rates of hospitalization for MI and mortality associated with CHD have decreased. The decline in CHD mortality is partially reflective of the change in the pattern of clinical presentations of ACS. ${ }^{4}$ There has been a substantial reduction in the incidence of STEMI and a subsequent increase in the incidence of NSTEMI. ${ }^{3}$ An analysis of 46,086 hospitalizations for ACS in a study conducted by Kaiser Permanente demonstrated that the percentage of STEMI cases decreased from $48.5 \%$ to $24 \%$ between 1999 and 2008. ${ }^{4}$ Despite the improvement in survival associated with ACS, this medical condition continues to have an association with fatal outcomes and places a burden on the entire health care system. A diagnosis of MI was responsible for approximately 125,000 deaths in the US in 2009, and ACS was associated with an estimated 625,000 hospital discharges in $2010 .{ }^{4}$ It is evident that there is room for improvement in the prevention and management of ACS.

\section{Diagnosis}

\section{Clinical Presentation}

A diagnosis of ACS should be considered in all patients presenting with ischemic symptoms. Clinical signs and symptoms of ischemia include various combinations of chest pain, upper extremity, mandibular or epigastric discomfort, dyspnea, diaphoresis, nausea, fatigue, or syncope. The pain and discomfort associated with an ACS event may occur with exertion or at rest and is often diffuse rather than localized. ${ }^{1}$ Pain radiating to the left arm, right shoulder, or both arms is more likely to be associated with MI, as is pain associated with diaphoresis. $^{5}$ These symptoms are not specific for MI and do not occur in all patients experiencing an ACS event. Atypical symptoms of ACS may occur in certain patient populations such as women, the elderly, diabetics, or postoperatively. In these situations, ACS may be associated with palpitations, cardiac arrest, or with an asymptomatic clinical presentation. ${ }^{1}$

\section{Past Medical History}

Obtaining a thorough past medical history in patients with suspected ACS is essential in assuring appropriate diagnosis and management. Factors that should be evaluated include the nature of a patient's angina symptoms, prior history of coronary artery disease (CAD), sex, age, and presence of risk factors for ACS. For patients who do not have these factors, consideration should be given to an alternative disease process. ${ }^{2}$

\section{Differential Diagnosis}

It is important to remember that MI represents myocardial necrosis due to myocardial ischemia. Other clinical conditions, such as pericarditis, dissecting aortic aneurysm, and mitral valve prolapse represent nonischemic, cardiac causes of myocardial injury and thus do not fall within the definition of ACS. In addition, there are several noncardiac conditions that may manifest with similar symptoms of ACS, including musculoskeletal pain, esophageal discomfort, pulmonary embolism, or anxiety. It is essential to determine the correct etiology of a patient's signs and symptoms to determine an appropriate management plan. ${ }^{1,2}$

\section{Cardiac Biomarkers}

Cardiac troponins are biochemical markers of myocardial damage. ${ }^{6}$ Increases in cardiac biomarkers, notably cardiac troponin (I or T), or the MB fraction of creatine kinase (CKMB), signify myocardial injury leading to necrosis of myocardial cells. Elevated cardiac biomarkers in and of themselves do not indicate the underlying mechanism of injury and do not differentiate between ischemic or nonischemic causes. ${ }^{1}$ There are several clinical conditions that have the potential to result in myocardial injury and cause elevations in cardiac biomarkers, including acute pulmonary embolism, heart failure (HF), end-stage renal disease, and myocarditis. ${ }^{7}$ As a result, cardiac biomarker elevations cannot be utilized in isolation to make a diagnosis of MI. ${ }^{1}$ The preferred cardiac biomarker is troponin, which has high clinical sensitivity and myocardial tissue specificity. An elevation in troponin concentration is based on specific assays and is defined as a value exceeding the 99th percentile of a normal reference population. At this level, sensitive cardiac troponin I assays have a positive likelihood ratio (LR) of $11-14$ and a negative LR of $0.06-0.15 .^{6}$ It is essential to detect a rise and/or fall in cardiac biomarkers to distinguish acute from chronic elevations in troponin concentrations, which may be 
associated with structural heart disease. Troponin levels should be measured on first assessment, within 6 hours of the onset of pain, and in the 6-12 hour time frame after onset of pain, due to the delayed increase in circulating levels of cardiac biomarkers (strength of recommendation A). In addition, it is important to understand that elevations in troponin may be seen for up to 2 weeks after the onset of myocardial necrosis. If troponin concentrations are unavailable, then CKMB should be measured. ${ }^{1}$ Ideally, both troponin and CKMB should be obtained during evaluation for ACS due to the different concentrations of these biomarkers over time and the added diagnostic value of serial testing (strength of recommendation A). ${ }^{2,3}$ For example, serial measurement of CKMB has a positive LR of 20 and negative LR of $0.22{ }^{8}$

\section{ECG Changes}

ECG abnormalities that are potentially reflective of myocardial ischemia include changes in the PR segment, the QRS complex, and the ST-segment. A meticulous evaluation of ECG changes can assist in estimating time of the event, amount of myocardium at risk, patient prognosis, and appropriate therapeutic strategies. ST-segment elevation found on an ECG is the hallmark sign of a STEMI. ${ }^{1}$ Similar to cardiac biomarkers, the ECG alone is often insufficient to make the diagnosis of an acute MI, and the sensitivity and specificity of ECG are increased by serial assessments. ${ }^{9}$ ECG changes such as ST deviation may be present in other conditions, such as left ven- tricular hypertrophy, left bundle branch block, or acute pericarditis. ${ }^{1}$

\section{Initial ACS Management \\ Early Management}

It is essential to evaluate patients with suspected ACS immediately to prevent potentially fatal clinical consequences and relieve ongoing ischemia. Early risk stratification should be performed that is inclusive of a patient's demographics and medical history, physical examination, ECG, and cardiac biomarker measurements (strength of recommendation A). A number of risk assessment tools have been developed to predict one's risk of recurrent ischemia or death following an ACS event. The Thrombosis in Myocardial Infarction (TIMI) risk score, a scoring system for UA and NSTEMI that incorporates seven variables on hospital admission, has been validated as a reliable predictor of subsequent ischemic events (Table 1). In addition, measurement of B-type natriuretic peptide may be considered to assist in predicting risk of morbidity and mortality in patients with suspected ACS. Early risk stratification can assist in determining whether a patient should be managed with either an early invasive strategy or an initial conservative strategy and can help determine the pharmacologic therapies that are recommended (Figure 1). ${ }^{2}$

\section{Coronary Revascularization}

In patients presenting with a STEMI, reperfusion therapy should be administered to all eligible patients with symptom onset within the prior 12 hours. ${ }^{3}$ Per-

Table 1. The Thrombosis in Myocardial Infarction (TIMI) Risk Score for Unstable Angina (UA)/Non-ST Elevated Myocardial Infarction (NSTEMI) ${ }^{2}$

\begin{tabular}{lcc}
\hline $\begin{array}{l}\text { Baseline Characteristics (1 point for each of } \\
\text { the following): }\end{array}$ & TIMI Risk Score (points) & Rate of Composite Endpoint $(\%)^{\ddagger}$ \\
\hline Age $\geq 65$ years; At least 3 risk factors for & $0-1$ & 4.7 \\
CAD ${ }^{*}$; Prior coronary stenosis $\geq 50 \%$; & 2 & 8.3 \\
ST segment deviation; At least 2 anginal & 3 & 13.2 \\
events in last 24 hours; Use of aspirin in & 4 & 19.9 \\
last 7 days; Elevated serum cardiac & 5 & 26.2 \\
biomarkers $^{\dagger}$ & $6-7$ & 40.9
\end{tabular}

*Risk factors include family history of CAD, hypertension, hypercholesterolemia, diabetes, or being a current smoker.

${ }^{\dagger} \mathrm{CKMB}$ fraction and/or cardiac-specific troponin level.

${ }^{\ddagger}$ All-cause mortality, new or recurrent MI, or severe recurrent ischemia requiring urgent revascularization through 14 days after randomization.

$\mathrm{CAD}$, coronary artery disease; $\mathrm{MI}$, myocardial infarction; CKMB, $\mathrm{MB}$ fraction of creatine kinase. 
Figure 1. Pharmacologic management of patients with Unstable Angina (UA)/Non-ST Elevated Myocardial Infarction (NSTEMI). ${ }^{2,11}$ ECG, electrocardiogram.
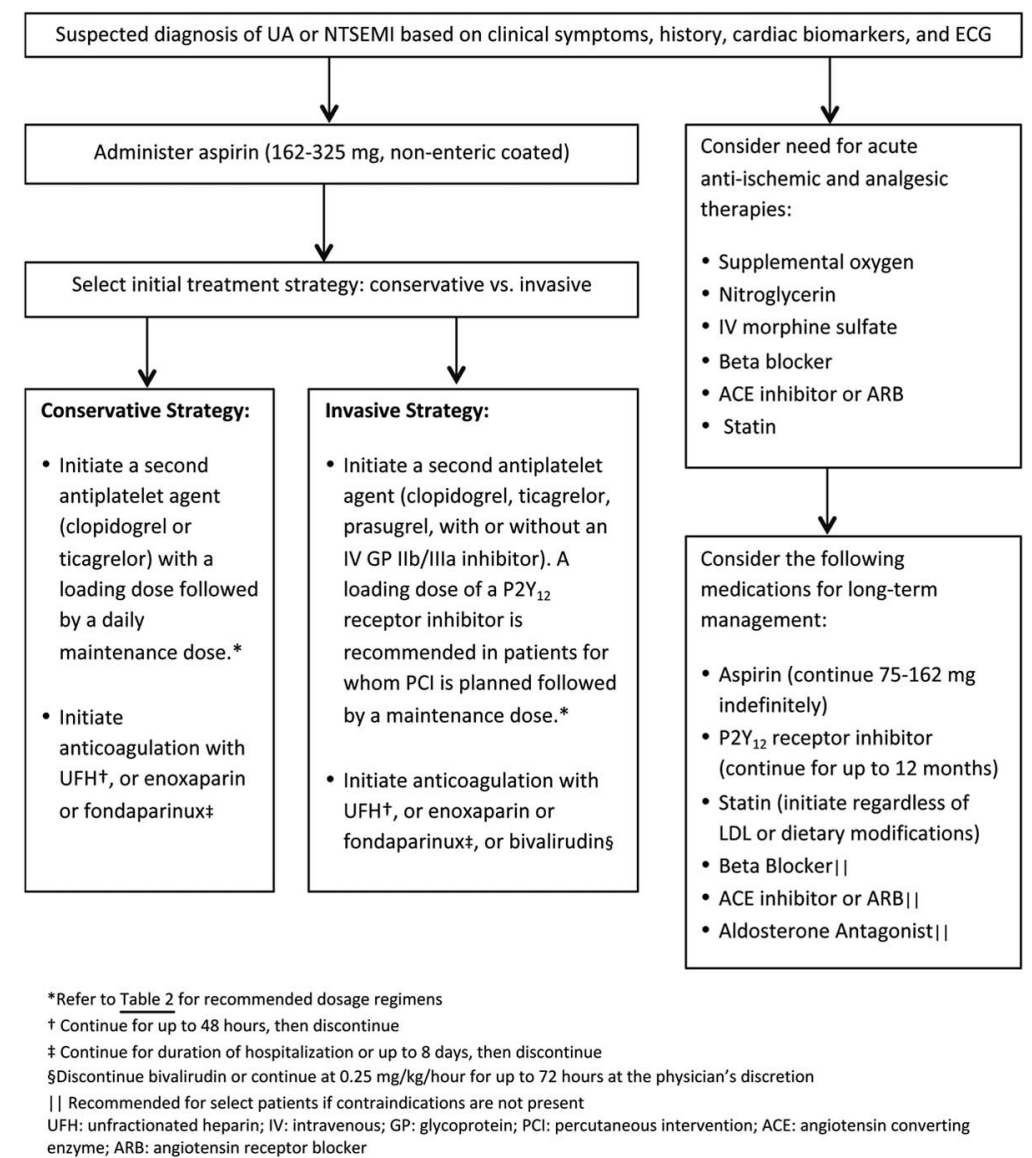

cutaneous coronary intervention (PCI) is the recommended method of reperfusion when it can be performed in a timely fashion, with the goal of time from first medical contact to device time of less than or equal to 90 minutes (strength of recommendation A). ${ }^{3}$ If patients are unable to get to a PCI-capable hospital within 120 minutes of a STEMI, then fibrinolytic therapy should be administered within 30 minutes of hospital arrival, provided there are no contraindications to its use (Figure 2) (strength of recommendation $\mathrm{A}){ }^{3}$ The benefit of an early invasive strategy of evaluation with coronary angiography for the treatment of patients initially presenting with NSTEMI or UA is less certain. A recent meta-analysis showed that current randomized controlled studies are inconclusive with regard to survival benefit associated with early (typically $<24$ hours) versus delayed invasive strategy in patients presenting with NSTEMI (OR, 0.83; 95\% CI, 0.64-1.09; $P=$ $.180) .{ }^{10}$ Early invasive coronary angiography is recommended in NSTEMI/UA patients with refractory angina or hemodynamic or electric instability (strength of recommendation A). Early invasive strategy is reasonable for higher-risk patients with NSTEMI/UA previously stabilized who do not have serious comorbidities (i.e., liver or pulmonary failure, cancer) or contraindications to the procedure (strength of recommendation B). ${ }^{11}$ Specific strategies utilized during revascularization are outside the scope of this review.

\section{Antithrombotic Agents}

Antiplatelet therapy, which reduces the risk of thrombosis by interfering with platelet release and aggregation, is a cornerstone in the management of ACS. ${ }^{11}$ Well-established antiplatelet therapies in the management of ACS include aspirin, adenosine diphosphate $\mathrm{P} 2 \mathrm{Y}_{12}$ receptor antagonists, and glycoprotein IIb/IIIa inhibitors. ${ }^{12}$ Aspirin should be started as soon as possible after an ACS event with an initial loading dose of $162-325 \mathrm{mg}$, and should be continued indefinitely, unless contraindicated 
Figure 2. Pharmacologic management of patients with ST-elevated myocardial infarction (STEMI). ${ }^{3}$ ECG, electrocardiogram.

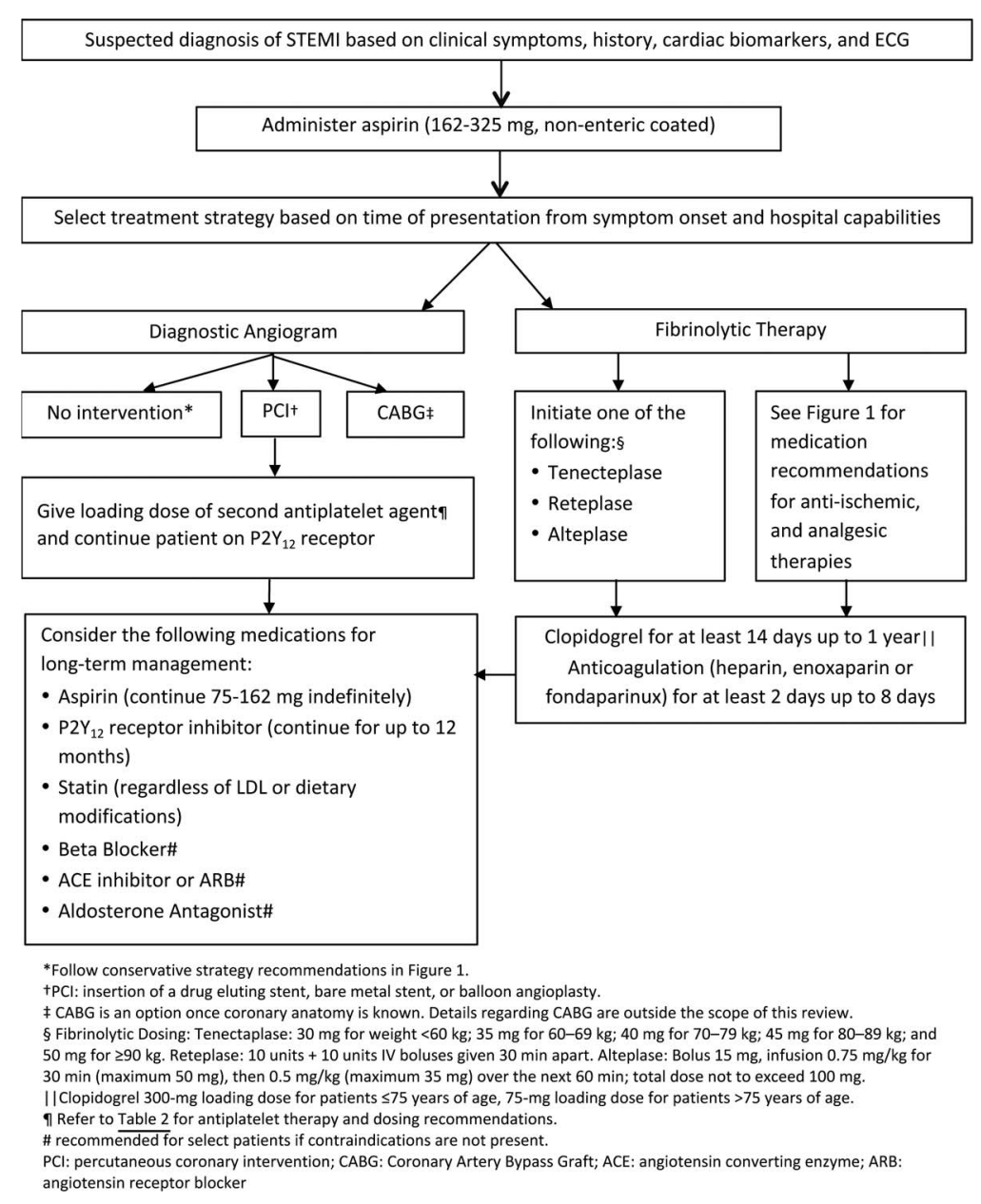

(strength of recommendation A). Aspirin $81 \mathrm{mg}$ daily is a reasonable maintenance dosing regimen given that higher doses have not shown any benefit over low-dose aspirin (level of evidence 1). ${ }^{13}$ In addition to aspirin, a $\mathrm{P} 2 \mathrm{Y}_{12}$ antagonist should be added for patients with ACS who are medically managed as well as those undergoing PCI (strength of recommendation $\mathrm{A}){ }^{3,11} \mathrm{P}_{2} \mathrm{Y}_{12}$ receptor antagonists frequently used in the management of ACS include clopidogrel (Plavix), prasugrel (Effient), and ticagrelor (Brilinta) (Table 2). ${ }^{14-16}$ Glycoprotein (GP) IIb/IIIa inhibitors have been shown to be efficacious when used during PCI in reducing ischemic complications; however, the use of GP IIb/ IIIa inhibitor therapy as part of triple antiplatelet therapy has also been associated with an increased bleeding risk. Recent research supports the strategy of selective use rather than routine upstream use of GP IIb/IIIa inhibitors as part of triple antiplatelet therapy with consideration of a patient's risk-benefit ratio (strength of recommendation A). ${ }^{11}$

\section{Clopidogrel}

Before the approval of new therapeutic agents, clopidogrel was a standard therapy for patients presenting with ACS. The benefit of adding clopidogrel to aspirin was first demonstrated in a 2001 trial in which patients presenting with UA or NSTEMI were randomly assigned to clopidogrel or placebo, in addition to aspirin, for a period of 3-12 months. The group assigned to dual antiplatelet therapy (DAPT) was shown to have a reduction in the primary outcome of cardiovascular death, nonfatal MI, or stroke as compared with placebo (9.3 vs $11.4 \%$; RR, 0.80 ; $95 \%$ CI, $0.72-0.90 ; \mathrm{P}<.001)$, with a number needed to treat (NNT) of 48 to prevent one such event. There was a significant increase in the rate of major bleeding associated with the group randomized to DAPT as 
Table 2. Antiplatelet Agents—-Oral P2Y 12 Inhibitors

\begin{tabular}{|c|c|c|c|}
\hline & Clopidogrel (Plavix) ${ }^{14}$ & Prasugrel (Effient) ${ }^{15}$ & Ticagrelor (Brilinta) ${ }^{16}$ \\
\hline \multicolumn{4}{|l|}{ Dosing } \\
\hline Loading dose for PCI & $600 \mathrm{mg}$ & $60 \mathrm{mg}$ & $180 \mathrm{mg}$ \\
\hline Loading dose for medical management & $300 \mathrm{mg}$ & & $180 \mathrm{mg}$ \\
\hline Maintenance dose & $75 \mathrm{mg}$ once daily & $\begin{array}{l}10 \mathrm{mg} \text { once daily (Consider } \\
5 \mathrm{mg} \text { once daily if } \\
\text { patient is }<60 \mathrm{~kg} \text { ) }\end{array}$ & $90 \mathrm{mg}$ twice daily \\
\hline Onset of action & $\begin{array}{l}6 \text { hours with } 300 \mathrm{mg} \text { dose } \\
2 \text { hours with } 600 \mathrm{mg} \text { dose }\end{array}$ & 30 minutes & 60 minutes \\
\hline Perioperative considerations & $\begin{array}{l}\text { Hold for } 5 \text { days prior to } \\
\text { surgery }\end{array}$ & $\begin{array}{l}\text { Hold for } 7 \text { days prior to } \\
\text { surgery }\end{array}$ & $\begin{array}{l}\text { Hold for } 5 \text { days prior to } \\
\text { surgery }\end{array}$ \\
\hline \multicolumn{4}{|l|}{ Clinical pearls } \\
\hline & $\begin{array}{l}\text { Genetic polymorphisms of the } \\
\text { CYP 2C19 enzyme lead to } \\
\text { variable antiplatelet effects }\end{array}$ & $\begin{array}{l}\text { Not FDA approved for } \\
\text { medical management, } \\
\text { only for patients } \\
\text { undergoing PCI }\end{array}$ & $\begin{array}{l}\text { Should not be used with } \\
\text { daily aspirin } \\
\text { maintenance doses of } \\
>100 \mathrm{mg}\end{array}$ \\
\hline & $\begin{array}{l}\text { Currently, the only generic } \\
\text { prescription option }\end{array}$ & $\begin{array}{l}\text { Contraindicated in patients } \\
\text { with prior stroke or TIA }\end{array}$ & $\begin{array}{l}\text { May cause dyspnea, } \\
\text { bradyarrythmias, and } \\
\text { ventricular pauses }\end{array}$ \\
\hline & & $\begin{array}{l}\text { No net benefit for patients } \\
<60 \mathrm{~kg} \text { and patients } \geq 75 \\
\text { years of age }\end{array}$ & $\begin{array}{l}\text { Undergoes CYP 3A4 } \\
\text { metabolism (concern } \\
\text { for drug interactions) }\end{array}$ \\
\hline & & & $\begin{array}{l}\text { Only agent shown to } \\
\text { have mortality benefit }\end{array}$ \\
\hline
\end{tabular}

PCI, percutaneous coronary intervention; FDA, U.S. Food and Drug Administration; TIA, transient ischemic attack.

opposed to those randomized to placebo (3.7 vs $2.7 \%$; RR, 1.38 ; $95 \%$ CI, $1.13-1.67 ; P=.001$ with a number needed to harm $(\mathrm{NNH})$ of 100 patients (level of evidence 1). ${ }^{17}$

\section{Prasugrel}

The 2007 landmark trial comparing clopidogrel to prasugrel showed that prasugrel was associated with a significant $2.2 \%$ absolute reduction in a composite endpoint of cardiovascular death, nonfatal MI, or nonfatal stroke as compared with clopidogrel, with a NNT of 46 patients over 6-15 months to prevent one cardiovascular disease outcome (9.9 vs $12.1 \%$; HR, 0.81 ; $95 \%$ CI, $0.73-0.90$; $P<.001)$. Randomization to prasugrel was also associated with a significant increase in the rate of bleeding, with a NNH of 166 patients for one bleeding event (2.4 vs $1.8 \%$; HR, $1.32 ; 95 \% \mathrm{CI}$, 1.03-1.68; $P=.03$ ) (level of evidence 1). Patients with body weight $<60 \mathrm{~kg}$ and patients $\geq 75$ years of age lacked a net clinical benefit. Patients with a history of stroke or transient ischemic attack had net harm with the use of prasugrel, and therefore its use in these patients is contraindicated. ${ }^{18}$ This trial was conducted in patients with moderate-to-high risk UA, NSTEMI, or STEMI who were referred for PCI, and prasugrel is U.S. Food \& Drug Administration (FDA) approved for the reduction of thrombotic cardiovascular events solely in patients with ACS who are to be managed with PCI. ${ }^{15}$ The role of prasugrel in patients with ACS who are not managed with PCI is yet to be defined.

\section{Ticagrelor}

The pivotal trial comparing ticagrelor to clopidogrel was conducted in patients with ACS, with or without ST-segment elevation, who had invasive or medical management planned. Ticagrelor was associated with a $1.9 \%$ absolute reduction in the composite outcome of vascular death, MI, or stroke as compared with clopidogrel, representing a NNT of 53 patients over the course of 12 months to prevent one outcome ( 9.8 vs $11.7 \%$; HR, $0.84 ; 95 \%$ CI, 0.77-0.92; $\mathrm{P}<.001)$. Ticagrelor was also associated with a $1.4 \%$ absolute reduction in all-cause mortality (4.5 vs $5.9 \%$; HR, 0.78; 95\% CI, $0.69-$ 0.89 ; NNT, 72 patients). There was no significant difference in the risk of major bleeding between treatment groups; however, the ticagrelor group had a higher rate of major bleeding not related to coronary artery bypass graft (CABG) surgery as compared with the clopidogrel group, representing 
an $\mathrm{NNH}$ of 142 patients to cause one event (4.5 vs $3.8 \%$; HR, 1.19; 95\% CI, 1.02-1.38; $P=.03$ ) (level of evidence 1). ${ }^{19}$

\section{Vorapaxar}

The most recent addition to the arsenal of antiplatelet agents was the approval of vorapaxar, a high-affinity oral antagonist that selectively inhibits thrombin from activating platelets through the protease-activated receptor 1 . Vorapaxar is indicated for the reduction of thrombotic cardiovascular events in patients with a history of MI or with peripheral arterial disease (PAD). ${ }^{20}$ This novel agent was approved by the FDA in 2014 based on the results of a large, phase III randomized controlled trial. This trial included 26,449 patients with a history of MI, ischemic stroke, or PAD who were randomly assigned to receive vorapaxar (2.5 $\mathrm{mg}$ daily) or placebo in addition to standard antiplatelet therapy for a median time of 30 months. Vorapaxar was associated with a $1.2 \%$ absolute risk reduction in the primary composite endpoint of death from cardiovascular causes, MI, or stroke as compared with placebo (HR, 0.87; 95\% CI, $0.80-$ 0.94; $P<.001$, NNT 84 patients). Moderate-tosevere bleeding was more common in the vorapaxar group as opposed to the placebo group (4.2 vs 2.5\%; HR, 1.66; 95\% CI, 1.43-1.93; $P<.001$, NNH 58 patients) (level of evidence 1). The role of vorapaxar in the management of ACS has not been fully elucidated and will likely evolve in the coming years. $^{21}$

\section{Anticoagulants}

The decision to use anticoagulation in addition to standard post-ACS treatment is challenging due to the intricate balance between safety and efficacy. During the initial management of ACS, parenteral anticoagulants are used in combination with antiplatelet agents (strength of recommendation A). Parenteral anticoagulants that may be used during this time include unfractionated heparin (UFH), low-molecular-weight heparin, fondaparinux, or bivalirudin. The choice of anticoagulant agent is dependent on the initial management strategy and the recommended duration of therapy varies based on the chosen agent (Figure 1). ${ }^{2,3}$ Although current guidelines do not recommend anticoagulants for post-ACS management following hospital discharge (unless indicated for a concomitant disease state), several studies have been conducted to investigate the use of anticoagulants in this setting (strength of recommendation B). ${ }^{22}$ A meta-analysis including 14 randomized controlled trials investigated the use of aspirin with warfarin versus aspirin alone in patients recovering from ACS to determine their effect on the incidence of ischemic events and the rate of bleeding (level of evidence 2). In trials included in this meta-analysis that targeted an international normalized ratio (INR) of $2-3$, the use of warfarin and aspirin was found to confer a significant reduction of major adverse events including all-cause death, nonfatal MI, and nonfatal thromboembolic stroke (OR, 0.73; 95\% CI, 0.63-0.84; $P<.0001)$ versus the use of aspirin alone (NNT of 33 patients to avoid one major adverse event). However, randomization to warfarin and aspirin was associated with a significantly greater rate of major bleeds (OR, 2.32; 95\% CI, 1.63-3.29; $P<.00001$ ), representing an $\mathrm{NNH}$ of 100 patients to cause a major bleed. ${ }^{23}$ While not routinely used in clinical practice, warfarin is FDA approved for reducing the risk of death, recurrent MI, and thromboembolic events after MI. ${ }^{24}$ In the past few years, three oral anticoagulants have been granted FDA approval in the US, including dabigatran (Pradaxa), rivaroxaban (Xarelto), and apixaban (Eliquis). ${ }^{25-27}$ Each have been studied in the setting of ACS but have not been granted FDA approval for prevention of thrombotic events associated with ACS [Table 3]. ${ }^{28-32}$

\section{Adjuvant Agents $\boldsymbol{\beta}$-Blockers}

Oral $\beta$-blocker therapy should be initiated within 24 hours of the onset of the event for patients presenting with UA, NSTEMI, or STEMI excluding patients with evidence of low-output state, signs of $\mathrm{HF}$, increased risk for cardiogenic shock, or other contraindications to therapy (strength of recommendation A). The use of intravenous $\beta$-blockers is reasonable in patients who are hypertensive and do not have any evidence of the states mentioned above. $\beta$-blockers reduce myocardial contractility, sinus node rate, and $\mathrm{AV}$ node conduction velocity by blocking the effects of catecholamines on $\beta$-receptors located in the myocardium. The net benefit of $\beta$-blockers is related to a decrease in cardiac work and reduction in myocardial oxygen demand. Studies 
Table 3. New Oral Anticoagulants-Data in Acute Coronary Syndrome (ACS)

\begin{tabular}{|c|c|c|c|}
\hline & Dabigatran (Pradaxa) & Rivaroxaban (Xarelto) $^{*}$ & Apixaban (Eliquis) \\
\hline Clinical trial & RE-DEEM (phase II) ${ }^{28}$ & $\begin{array}{l}\text { ATLAS-ACS-2-TIMI-51 (phase } \\
\text { III) }{ }^{29}\end{array}$ & APPRAISE-2 (phase III) ${ }^{32}$ \\
\hline Patient population & $\begin{array}{l}1861 \text { patients presenting with } \\
\text { STEMI or NSTEMI }\end{array}$ & $\begin{array}{l}7817 \text { patients presenting with } \\
\text { STEMI }\end{array}$ & $\begin{array}{l}7392 \text { patients with recent ACS } \\
\text { and } \geq 2 \text { additional risk } \\
\text { factors for recurrent } \\
\text { ischemic events }\end{array}$ \\
\hline Primary outcome & $\begin{array}{l}\text { Composite of major or clinically } \\
\text { relevant minor bleeding }\end{array}$ & $\begin{array}{l}\text { Composite of CV death, MI, or } \\
\text { stroke }\end{array}$ & $\begin{array}{l}\text { Efficacy: a composite of CV } \\
\quad \text { death, MI, or stroke } \\
\text { Safety: major TIMI bleeding }\end{array}$ \\
\hline \multirow[t]{2}{*}{ Results } & \multirow{2}{*}{$\begin{array}{l}\text { There was a dose-dependent } \\
\text { increase in bleeding with } \\
\text { dabigatran compared with } \\
\text { placebo: HR, } 1.77 \text { (95\% CI, } \\
0.70-4.50) \text { for } 50 \mathrm{mg} \text {; HR, } \\
2.17 \text { (95\% CI, 0.88-5.31) for } \\
75 \mathrm{mg} \text {; HR, } 3.92 \text { (95\% CI, } \\
1.72-8.95) \text { for } 110 \mathrm{mg} \text {; and } \\
\text { HR, } 4.27 \text { (95\% CI, 1.86-9.81) } \\
\text { for } 150 \mathrm{mg} \text { (all given twice } \\
\text { daily) }\end{array}$} & $\begin{array}{l}\text { Rivaroxaban reduced the primary } \\
\text { efficacy endpoint of CV death, } \\
\text { MI, or stroke compared with } \\
\text { placebo (8.4 vs } 10.6 \% \text {; HR, } \\
\text { 0.81; } 95 \% \text { CI, } 0.67-0.97 ; P= \\
.019)\end{array}$ & $\begin{array}{l}\text { There was no significant } \\
\text { reduction in the occurrence } \\
\text { of ischemic events when } \\
\text { comparing apixaban to } \\
\text { placebo (7.5 vs } 7.9 \% \text { HR, } \\
0.95 ; 95 \% \mathrm{CI}, 0.80-1.11 ; \\
P=.51)\end{array}$ \\
\hline & & $\begin{array}{l}\text { Rivaroxaban increased non- } \\
\text { CABG TIMI major bleeding } \\
(2.2 \text { vs } 0.6 \% ; P=.001) \text { and } \\
\text { ICH }(0.6 \text { vs } 0.1 \% ; P=.015) \\
\text { without a significant increase } \\
\text { in fatal bleeding }(0.2 \text { vs } 0.1 \% \text {, } \\
P=.51)\end{array}$ & $\begin{array}{l}\text { Apixaban demonstrated an } \\
\text { increase in major TIMI } \\
\text { bleeding compared with } \\
\text { placebo (1.3 vs } 0.5 \% \text { HR, } \\
2.59 ; 95 \% \mathrm{CI}, 1.50-4.46 ; \\
P=.001)\end{array}$ \\
\hline Conclusions & $\begin{array}{l}\text { Dabigatran was associated with a } \\
\text { dose-dependent increase in } \\
\text { bleeding events in this patient } \\
\text { population when compared to } \\
\text { placebo }\end{array}$ & $\begin{array}{l}\text { Rivaroxaban reduced CV events } \\
\text { in this patient population } \\
\text { when compared with placebo, } \\
\text { albeit at an increased risk of } \\
\text { bleeding }\end{array}$ & $\begin{array}{l}\text { Apixaban increased the } \\
\text { frequency of major bleeds } \\
\text { without a significant } \\
\text { reduction in ischemic events } \\
\text { compared with placebo }\end{array}$ \\
\hline
\end{tabular}

*The FDA has denied the proposed expanded indication for rivaroxaban as a treatment for patients with ACS to reduce the risk of MI, stroke, death, or stent thrombosis. ${ }^{30}$ Rivaroxaban $2.5 \mathrm{mg}$ twice daily is approved in Europe for secondary prevention of ACS in combination with standard antiplatelet therapy. ${ }^{31}$

APPRAISE-2, Apixaban for Prevention of Acute Ischemic Events 2; ATLAS-ACS-2-TIMI-51, Anti-Xa Therapy to Lower Cardiovascular Events in Addition to Standard Therapy in Subjects with Acute Coronary Syndrome-Thrombolysis In Myocardial Infarction-51; CABG, coronary artery bypass grafting; CV, cardiovascular; HR, hazard ratio; ICH, intracranial hemorrhage; MI, myocardial infarction; RE-DEEM, The Randomized Dabigatran Etexilate Dose Finding Study in Patient with Acute Coronary Syndromes Post Index Event with Additional Risk Factors for Cardiovascular Complications Also Receiving Aspirin and Clopidogrel. STEMI, ST-elevated myocardial infarction; NSTEMI, non-ST elevated myocardial infarction; TIMI, thrombosis in myocardial infarction; CI, confidence interval.

investigating the impact of $\beta$-blockers on mortality in patients with ACS have variable results based on differences in route of administration, time of administration from event onset, and patient population. ${ }^{33,34}$ There is, however, sufficient evidence to recommend $\beta$-blockers as a routine part of care in this patient population (strength of recommendation B). ${ }^{2,3}$ Efforts should be made to start a $\beta$-blocker in the post-MI setting before discharge unless contraindicated or not tolerated (strength of recommendation A). There is debate regarding the recommended duration of $\beta$-blocker use in the post-MI setting. The evidence suggesting the long-term use of $\beta$-blockers post MI is largely from trials conducted before the widespread use of antiplatelet agents and routine reperfusion therapy. Data suggests that the benefits of $\beta$-blockers emerge in the early phase after MI and benefits are more prevalent among high-risk patients. The duration of benefit of long-term oral $\beta$-blocker therapy is uncertain at this time. Many practitioners choose to continue $\beta$-blockers indefinitely despite the lack of firm evidence. If patients are experiencing side effects from $\beta$-blocker use, it may be reasonable to discontinue therapy at least 1 year after an MI (strength of recommendation B) ${ }^{35}$ For patients who are unable to take $\beta$-blockers and experience recurrent ischemia, consideration should be given to starting a nondihydropyridine calcium channel blocker (ie, verapamil or diltiazem) in the absence of clinically significant left ventricular dysfunction (strength of recommendation A). ${ }^{2,3}$ 


\section{Inbibitors of the Renin-Angiotensin System}

An angiotensin-converting enzyme (ACE) inhibitor or angiotensin receptor blocker (ARB) should be initiated within the first 24 hours of patients presenting with ACS who have pulmonary congestion, HF, STEMI with anterior location, or left ventricular ejection fraction (LVEF) $\leq 40 \%$ in the absence of contraindications to therapy (strength of recommendation A). ${ }^{2,3}$ ACE inhibitors have been shown to reduce mortality in a broad spectrum of patients following MI, including those with and without left ventricular dysfunction (level of evidence 1). ${ }^{36-39}$ ACE inhibitors have also been studied in patients with stable CAD, which have shown conflicting effects on mortality and vascular events (level of evidence 2). ${ }^{40-42}$ Patients with stable CAD who are not medically optimized (ie, cannot tolerate a $\beta$-blocker or statin), who are not able to be revascularized, and/or who have poorly controlled diabetes have shown mortality benefit with continued treatment with ACE inhibitors. ${ }^{40}$ On the contrary, revascularized patients with stable CAD, without significant comorbidities, who are on optimal medication management, have not shown this long-term benefit. ${ }^{42}$ The decision to continue an ACE inhibitor long-term in patients with a history of ACS should be individualized with concomitant disease states considered. Aldosterone antagonists (ie, spironolactone, eplerenone) have also been studied in the post-ACS setting and have been found to reduce morbidity and mortality in select patient populations (level of evidence 1) ${ }^{43,44}$ Initiation of an aldosterone antagonist is recommended after an ACS event for patients who are on therapeutic doses of an ACE inhibitor or $\mathrm{ARB}$ and $\beta$-blocker with an LVEF $\leq 40 \%$ and either symptomatic HF or diabetes mellitus (strength of recommendation A). When initiating inhibitors of the renin-angiotensin system, it is important to monitor for adverse effects associated with these agents including hyperkalemia, elevations in serum creatinine, and hypotension. . $^{2,3}$

\section{HmG-coenzyme A Reductase Inbibitors}

It is recommended to initiate or continue statin therapy in all patients presenting with ACS and no contraindications to its use (strength of recommendation A). ${ }^{2,3}$ High-intensity statin therapy following an ACS event was shown to confer an absolute risk reduction of $3.9 \%$ as compared with a moderate intensity statin for the composite endpoint of death from any cause, recurrent MI, UA requiring rehospitalization, revascularization, and stroke (22.4 vs $26.3 \%$; RR, $16 \%$; $95 \%$ CI, $5-26 \%$; $P=$ $.005)$, representing an NNT of 26 for a time period of 2 years (level of evidence 1). ${ }^{45}$ Statin therapy has been shown to be beneficial following ACS even in patients with baseline low-density lipoprotein cholesterol levels of $<70 \mathrm{mg} / \mathrm{dL} .^{2,3}$ Recently published American College of Cardiology and American Heart Association Guidelines on treatment of cholesterol recommend high intensity statins (ie, atorvastatin, $\geq 40 \mathrm{mg}$ daily or rosuvastatin, $\geq 20 \mathrm{mg}$ daily) for high-risk patients, which include patients who have an ACS event. Lower-dose statins can be considered if patients are $>75$ years old or if patients cannot tolerate high-intensity statins (strength of recommendation A). ${ }^{46}$

\section{Conclusion}

ACS is a potentially life-threatening condition that affects millions of individuals each year. Despite declining rates of hospitalization for MI, the identification and prevention of ACS continues to be an important public health concern. Over the past several years, studies have led to an improved understanding of the pathophysiology of ACS and advancements have been made in the medical management of this condition. Initial ACS management should include risk stratification, appropriate pharmacologic management including DAPT, anticoagulation and appropriate adjuvant therapies, and a decision to pursue an early invasive or conventional treatment strategy. Long-term management following an ACS event should follow evidence-based recommendations and should be individualized to each patient.

\section{References}

1. Thygesen K, Alpert JS, Jaffe AS, et al. Third universal definition of myocardial infarction. Circulation 2012;126:2020-2035.

2. Anderson JL, Adams AD, Antman SM, et al. ACC/ AHA 2007 guidelines for the management of patients with unstable angina/non ST-elevation myocardial infarction: A report of the American College of Cardiology/American Heart Association Task Force on Practice Guidelines (Writing Committee to Revise the 2002 Guidelines for the Management of Patients With Unstable Angina/Non ST-Elevation Myocardial Infarction): Developed in collaboration with the American College of Emergency Physicians, the Society for Cardiovascular Angiogra- 
phy and Interventions, and the Society of Thoracic Surgeons: Endorsed by the American Association of Cardiovascular and Pulmonary Rehabilitation and the Society for Academic Emergency Medicine. Circulation 2007;116:e148-e304.

3. O'Gara PT, Kushner FG, Ascheim DD, et al. 2013 ACCF/AHA guideline for the management of STelevation myocardial infarction: A report of the American College of Cardiology Foundation/American Heart Association Task Force on Practice Guidelines. J Am Coll Cardiol 2013;61:e78-e140.

4. Go AS, Mozaffarian D, Roger VL, et al. Heart disease and stroke statistics-2013 update: A report from the American Heart Association. Circulation 2013;127:e6-e245.

5. Panju AA, Hemmelgarn BR, Guyatt GH, Simel DL. The rational clinical examination. Is this patient having a myocardial infarction? JAMA 1998;280:12561263.

6. Reichlin T, Hochholzer W, Bassetti S, et al. Early diagnosis of myocardial infarction with sensitive cardiac troponin assays. N Engl J Med 2009;361:858867.

7. Korff S, Katus HA, Giannitsis E. Differential diagnosis of elevated troponins. Heart 2006;92:987-993.

8. Balk EM, Ioannidis JP, Salem D, Chew PW, Lau J. Accuracy of biomarkers to diagnose acute cardiac ischemia in the emergency department: A meta-analysis. Ann Emerg Med 2001;37:478-494.

9. Fesmire FM, Percy RF, Bardoner JB, Wharton DR, Calhoun FB. Usefulness of automated serial 12-lead ECG monitoring during the initial emergency department evaluation of patients with chest pain. Ann Emerg Med. 1998;31:3-11.

10. Navarese EP, Gurbel PA, Andreotti F, et al. Optimal timing of coronary invasive strategy in non-ST-segment elevation acute coronary syndromes: A systematic review and meta-analysis. Ann Intern Med 2013; 158:261-270.

11. Jneid H, Anderson JL, Wright RS, et al. 2012 ACCF/AHA focused update of the guideline for the management of unstable angina/non-ST segment myocardial infarction (updating the 2007 guideline and replacing the 2011 focused update): A report of the American College of Cardiology Foundation/ American Heart Association Task Force on Practice Guidelines J Am Coll Cardiol. 2012;60:645-681.

12. Cheng JW. Updates in antiplatelet agents used in cardiovascular diseases. J Cardiovasc Pharmacol Ther 2013;18:514-524.

13. Mehta SR, Tanguay JF, Eikelboom JW, et. al. Double-dose versus standard-dose clopidogrel and high-dose versus low-dose aspirin in individuals undergoing percutaneous coronary intervention for acute coronary syndromes (CURRENTOASIS 7): A randomised factorial trial. Lancet 2010;376:1233-1243.
14. Sanofi Aventis. Clopidogrel (Plavix) package insert. Bridgewater NJ; 2013.

15. Eli Lilly and Company. Prasugrel (Effient) package insert. Indianapolis, IN; 2009.

16. Astra Zeneca LP. Ticagrelor (Brilinta) package insert. Wilmington, DE; 2011.

17. Yusuf S, Zhao F, Mehta SR, et al. Effects of clopidogrel in addition to aspirin in patients with acute coronary syndromes without ST-segment elevation. N Engl J Med 2001;345:494-502.

18. Wiviott SD, Braunwald E, McCabe CH, et al. Prasugrel versus clopidogrel in patients with acute coronary syndromes. N Engl J Med 2007;357:20012015.

19. Wallentin L, Becker RC, Budaj A, et al. Ticagrelor versus clopidogrel in patients with acute coronary syndromes. N Engl J Med 2009;357:1045-1057.

20. Merck and Co, Inc. Vorapaxar (Zontivity) package insert. Whitehouse Station NJ; 2014.

21. Morrow DA, Braunwald E, Bonaca MP, et al. Vorapaxar in the secondary prevention of atherothrombotic events. N Engl J Med 2012;366:1404-1413.

22. Ganetsky VS, Hadley DE, Thomas TF. Role of Novel and Emerging Oral Anticoagulants for Secondary Prevention of Acute Coronary Syndromes. Pharmacotherapy. 2014;34:590-604.

23. Andreotti F, Testa L, Biondi-Zoccai GG, Crea F. Aspirin plus warfarin compared to aspirin alone after acute coronary syndromes: An updated and comprehensive meta-analysis of 25,307 patients. Eur Heart J 2006;27:519-526.

24. Bristol-Myers Squibb. Warfarin (Coumadin) package insert. Princeton NJ; 1954.

25. Boehringer Ingelheim Pharmaceuticals, Inc. Dabigatran (Pradaxa) package insert. Ridgefield CT; 2010.

26. Janssen Pharmaceuticals, Inc. Rivaroxaban (Xarelto) package insert. Titusville NJ; 2011.

27. Bristol-Myer Squibb. Apixaban (Eliquis) package insert. Princeton NJ; 2012.

28. Oldgren J, Budaj A, Granger CB, et al. Dabigatran vs. placebo in patients with acute coronary syndromes on dual antiplatelet therapy: A randomized, double-blind, phase II trial. Eur Heart J 2011;32: 2781-2789.

29. Mega JL, Braunwald E, Murphy SA, et al. Rivaroxaban in patients stabilized after an ST-elevation myocardial infarction: Results from the ATLAS ACS 2-TIMI 51 trial. J Am Coll Cardiol 2013;61:853859.

30. Johnson \& Johnson. FDA issues complete response letters for use of XARELTO (rivaroxaban) to reduce the risk of secondary cardiovascular events and stent thrombosis in patients with acute coronary syndrome [press release]. February 14, 2014.

31. Bayer Healthcare. Bayer's Xarelto approved in the EU for secondary prevention after an acute coronary syndrome [press release]. May 24, 2013. Available 
from http://press.health.care/bayer.com/en/press/ news-details-page.php/15050/2013-0292. Accessed April 18, 2014.

32. Alexander JH, Lopes RD, James S, et al. Apixaban with antiplatelet therapy after acute coronary syndrome. N Engl J Med 2011;365:699-708.

33. Chen ZM, Jiang LX, Chen YP, et al. Addition of clopidogrel to aspirin in 45,852 patients with acute myocardial infarction: Randomised placebo-controlled trial. Lancet. 2005;366:1607-1621.

34. Dargie HJ. Effect of carvedilol on outcome after myocardial infarction in patients with left-ventricular dysfunction: The CAPRICORN randomised trial. Lancet. 2001;357:1385-1390.

35. Kezerashvili A, Marzo K, De Leon J. Beta blocker use after acute myocardial infarction in the patient with normal systolic function: When is it "ok" to discontinue? Curr Cardiol Rev. 2012;8:77-84.

36. Pfeffer MA, Braunwald E, Moyé LA, et al. Effect of captopril on mortality and morbidity in patients with left ventricular dysfunction after myocardial infarction. Results of the survival and ventricular enlargement trial. The SAVE Investigators. N Engl J Med 1992;327:669-677.

37. Kober L, Torp-Pedersen C, Carlsen JE, et al. A clinical trial of the angiotensin-converting-enzyme inhibitor trandolapril in patients with left ventricular dysfunction after myocardial infarction. Trandolapril Cardiac Evaluation (TRACE) Study Group. N Engl J Med 1995;333:1670-1676.

38. ISIS-4: A randomised factorial trial assessing early oral captopril, oral mononitrate, and intravenous magnesium sulphate in 58,050 patients with suspected acute myocardial infarction. ISIS-4 (Fourth International Study of Infarct Survival) Collaborative Group. Lancet. 1995;345:669-685.

39. GISSI-3: Effects of lisinopril and transdermal glyceryl trinitrate singly and together on 6-week mortality and ventricular function after acute myocardial infarction. Gruppo Italiano per lo Studio della Sopravvivenza nell'infarto Miocardico. Lancet. 1994; 343:1115-1122.

40. Yusuf S, Sleight P, Pogue J, Bosch J, Davies R, Dagenais G. Effects of an angiotensin-convertingenzyme inhibitor, ramipril, on cardiovascular events in high-risk patients. The Heart Outcomes Prevention Evaluation Study Investigators. N Engl J Med. 2000;342:145-153.

41. Fox KM. Efficacy of perindopril in reduction of cardiovascular events among patients with stable coronary artery disease: Randomised, double-blind, placebo-controlled, multicentre trial (the EUROPA study). Lancet. 2003;362:782-788.

42. Braunwald E, Domanski MJ, Fowler SE, et al. Angiotensin-converting-enzyme inhibition in stable coronary artery disease. N Engl J Med. 2004;351:2058-2068.

43. Pitt B, Zannad F, Remme WJ, et al. The effect of spironolactone on morbidity and mortality in patients with severe heart failure. Randomized Aldactone Evaluation Study Investigators. N Engl J Med 1999;341:709-717.

44. Pitt B, Williams G, Remme W, et al. The EPHESUS trial: Eplerenone in patients with heart failure due to systolic dysfunction complicating acute myocardial infarction. Eplerenone post-AMI heart failure efficacy and survival study. Cardiovasc Drugs Ther 2001;15:79-87.

45. Cannon CP, Braunwald E, McCabe CH, et al. Intensive versus moderate lipid lowering with statins after acute coronary syndromes. N Engl J Med 2004; 350:1495-1504.

46. Stone NJ, Robinson J, Lichtenstein AH, et al. 2013 ACC/AHA guideline on the treatment of blood cholesterol to reduce atherosclerotic cardiovascular risk in adults: A report of the American College of Cardiology/American Heart Association Task Force on Practice Guidelines. J Am Coll Cardiol. 2014;63(25 Pt B):2889-2934. 